\title{
Wind-tunnel study of snowdrift around avalanche defence structures
}

\author{
Christian JAEDiCKe, ${ }^{1,2}$ Florence NAAIM-BOUVET, ${ }^{1}$ Matthias GRANiG ${ }^{1,3}$ \\ ${ }^{1}$ Cemagref, Domaine universitaire, 2 rue de la Papeterie, BP 76, 38402 Saint-Martin-d'Hères Cedex, France \\ ${ }^{2}$ Norwegian Geotechnical Institute, P.O. Box 3930, Ullevål Stadion, N-0806 Oslo, Norway \\ E-mail: cj@ngi.no \\ ${ }^{3}$ BOKU Wien, Gregor Mendel Straße 33, A-1180 Vienna, Austria
}

\begin{abstract}
Avalanche defence structures such as retarding dams and breaking mounds are widely used to protect residential areas and other kinds of infrastructure. The effect of the defence structures depends largely on their effective height relative to the velocity, volume and flow depth of the avalanche. Snow depositions from earlier avalanches as well as from drifting snow can significantly alter the effective height of defence structures. Different designs of avalanche-breaking mounds and retarding dams were tested in the Cemagref (Grenoble, France) wind tunnel for their effect on drifting snow. Examples included dams and mounds of different sizes and heights. The models were tested in a wind tunnel with sand particles subjected to different wind directions. The resulting depositions were scanned with a laser system to obtain a three-dimensional picture of the accumulation pattern. The results show that the accumulated snow varies widely with the design of the structure for a given wind direction. Most snow is accumulated around narrow mounds, with least accumulation observed around mounds covering a smaller relative area of the avalanche path. The data obtained can be used to study the effect of the depositions on the retarding effect of the avalanche defence structures. However, because the similarity criteria for studying the interaction between structures and saltating particles in a wind tunnel cannot be met, the transfer of the results to reality must be performed with caution.
\end{abstract}

\section{NOTATION}

$C_{\mathrm{D}} \quad$ Drag coefficient

$c_{\mathrm{p}} \quad$ Empirical coefficient of particle characteristics

$D_{\mathrm{p}} \quad$ Particle diameter $(\mathrm{m})$

$g \quad$ Gravitational acceleration $\left(\mathrm{m}^{2} \mathrm{~s}^{-2}\right)$

$H \quad$ Reference height $(\mathrm{m})$

$h \quad$ Vertical distance $(\mathrm{m})$

$L \quad$ Reference length (m)

$l \quad$ Horizontal distance $(\mathrm{m})$

$m \quad$ Model

$p \quad$ Prototype

$Q \quad$ Mass flow rate $\left(\mathrm{kg} \mathrm{m}^{-1} \mathrm{~s}^{-1}\right)$

$t \quad$ Experiment duration (s)

$U \quad$ Reference speed $\left(\mathrm{m} \mathrm{s}^{-1}\right)$

$U_{0} \quad$ Threshold speed at a reference height $\left(\mathrm{m} \mathrm{s}^{-1}\right)$

$U_{\mathrm{F}} \quad$ Particle settling velocity $\left(\mathrm{m} \mathrm{s}^{-1}\right)$

$u_{*} \quad$ Shear velocity $\left(\mathrm{m} \mathrm{s}^{-1}\right)$

$u_{* \text { th }} \quad$ Threshold shear velocity $\left(\mathrm{m} \mathrm{s}^{-1}\right)$

$V_{0} \quad$ Dimensionless volume $\left(V_{0} / L H^{2}\right)$

$v \quad$ Dynamic viscosity $\left(\mathrm{N} \mathrm{s} \mathrm{m}^{-2}\right)$

$\rho \quad$ Air density $\left(\mathrm{kg} \mathrm{m}^{-3}\right)$

$\sigma \quad$ Particle density $\left(\mathrm{kg} \mathrm{m}^{-3}\right)$

\section{INTRODUCTION}

Wind-transported snow is a common phenomenon in cold, windy areas such as mountainous or polar regions. The wind erodes snow from areas of high wind speeds, and deposits the snow in areas of low wind speeds. This process significantly alters the snowpack around obstacles and artificial structures. The resulting snowdrifts often cause problems for infrastructure and road maintenance and contribute significantly to the loading of avalanche release areas (Mellor, 1965).

Full-scale experiments with drifting snow are time- and resource-consuming projects. They can be replaced by wind-tunnel or outdoor small-scale modelling. A set of similarity criteria allows the comparison of model results with the prototype scale, if they can be fulfilled.

Avalanche defence structures are used in common avalanche paths to break the flow of the avalanche and to retard the flow past the defence structure. There are several designs, ranging from dams covering $100 \%$ of the avalanche path, to circular mounds of natural gravel, to concrete structures of various designs. Hákonardóttir and others (2001) tested different configurations of breaking dams and mounds, varying the height of the structures and the percentage of avalanche path covered. They used sand and glass beads in chutes of various lengths, simulating wet snow avalanches. Their results show that in certain cases a row of mounds can be more effective than a continuous dam, due to increased mixing.

The efficiency of avalanche defence structures can be reduced significantly by previous avalanches or driftingsnow depositions. Snowdrifts can easily reach half of the 


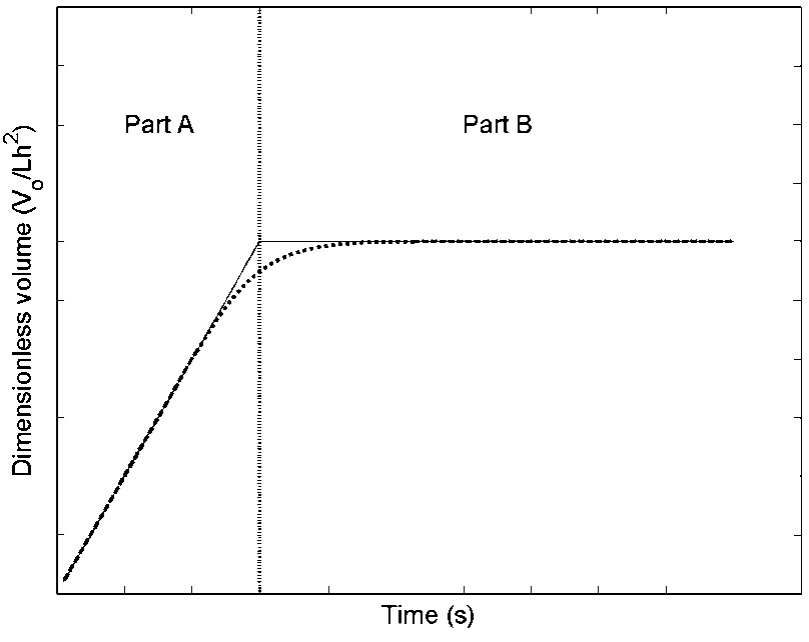

Fig. 1. Idealized growth of snowdrift.

height of the structure, reducing its effectiveness by an order of four.

The objective of this study is to test different designs of defence structures and their effect on drifting snow. The results will provide additional information for the best choice of a defence structure on a given site.

\section{THEORETICAL BACKGROUND}

\subsection{Similitude requirements for modelling a snowdrift}

Physical modelling permits the study of drifting snow in small-scale laboratory models. Wind-tunnel modelling has been used since the 1930s (Finney, 1939). The transfer of a model result to full scale requires the application of similarity criteria for static and dynamic parameters. In practice, the many modelling parameters cannot all be satisfied simultaneously. A number of studies have been made of similarity criteria problems and their optimization (Iversen, 1980, 1984; Tabler, 1980; Anno, 1984; Kind, 1986). The authors disagree in their results concerning the most important set of requirements for modelling drifting snow. A short discussion of the different points of view is presented.

If the following requirements are satisfied:

geometrical dimensions are reduced by the same factor

the model flow is turbulent

the angle of repose between model and prototype is the same,

then significant disagreement exists within the scientific community concerning the appropriate particles and wind speed.

\subsection{Particles used}

The process of saltation (rather than turbulent diffusion) must be the prevailing transport mode in the physical modelling. To ensure this condition, the ratio of the particle-settling velocity to the threshold friction velocity $U_{\mathrm{F}} / u_{* \text { th }}$ must be $>1$ (Iversen, 1980). If the particles' Reynolds number
$D_{\mathrm{p}} u_{* \mathrm{th}} / v$ is $>3.5$, the fluid threshold shear velocity is equal to

$$
u_{* \mathrm{th}}=c_{\mathrm{p}} \sqrt{\frac{(\sigma-\rho)}{\rho} g D_{\mathrm{p}}},
$$

where $c_{\mathrm{p}}$ is an empirical coefficient dependent on grain characteristics (0.1 for sand-sized particles (Bagnold, 1941)). If the particle Reynolds number is $<3.5$, the surface can be considered smooth and a relatively greater drag is required to set the first grain in motion. Consequently, if model particles are not transported by compressed air (Anno, 1984) or the saltation is not maintained by an elevated particle dispenser (Michaux and others, 2002), it is not possible to apply the geometrical-scale requirements to the particle size. Otherwise the turbulent diffusion will be the predominant process.

In most cases, the model particles diameter is close to $100 \mu \mathrm{m}$, allowing a low value for the friction threshold velocity to be obtained which is the typical size of blowing snow particles. As a result, the saltation trajectory is not reduced to the same geometrical scale. For successful modelling, the trajectories must be as small as possible in such a way that the maximum saltation length becomes smaller than the maximum snowdrift length.

\subsection{Wind-speed criteria}

The Froude number $U^{2} / H g$, the densimetric Froude number $\left(\rho U^{2}\right) /(\sigma g H)$ or the modified densimetric Froude number $\left[\rho U^{2}\left(1-U_{0} / U\right)\right] /(\sigma g H)$ is proposed to be the deciding criterion for the wind speeds used during snowdrift modelling (Iversen, 1980, 1984; Tabler, 1980; Kind, 1986). In contrast, Anno (1984) proposes the ratio of shear velocity vs threshold shear velocity $u_{*} / u_{* \text { th }}$. The Froude number is obtained from the particle trajectory equation of motion. In this case, it is closely linked to $\left(C_{\mathrm{D}} \rho H\right) /\left(\sigma D_{\mathrm{p}}\right)$ (e.g. if both parameters are satisfied, a significant reduction of the scale of the prototype using air as the model fluid is not possible). Naaim-Bouvet (1994) showed that the Froude number by itself is not a relevant parameter and the windspeed ratio $u_{*} / u_{* \text { th }}$ is more appropriate for snowdrift modelling. Moreover, if the two requirements $U^{2} / \mathrm{Hg}$ and $\left(C_{\mathrm{D}} \rho H\right) /\left(\sigma D_{\mathrm{p}}\right)$ are satisfied, the wind-speed ratio $u_{*} / u_{* \mathrm{th}}$ is automatically matched between model and prototype (Naaim-Bouvet, 1997). Due to experimental difficulties, it is hard to determine the friction velocity inside the saltation layer. The presence of particles in the air stream modifies the wind-speed profile due to the momentum extracted by the grains during aeolian transport. The fetch (length of deposed particles on the floor of the wind tunnel) and thus the particle-concentration profiles have a perceptible effect on the wind-speed profiles (Naaim-Bouvet and Naaim, 1998). Consequently, the wind-speed ratio as well as the fetch of particles must be the same during all the experiments.

\subsection{Application in our case}

The growth of snowdrift generated by an obstacle can be characterized by two states (Fig. 1). After a linear increase in accumulated volume, the drift reaches a saturated equilibrium. The dimensionless volume is no longer timedependent. Considering that the desired drift features are appropriately modelled if the ratio $u_{*} / u_{* \text { th }}$ is satisfied (Anno, 1984; Naaim-Bouvet, 1994), it is possible to compare 


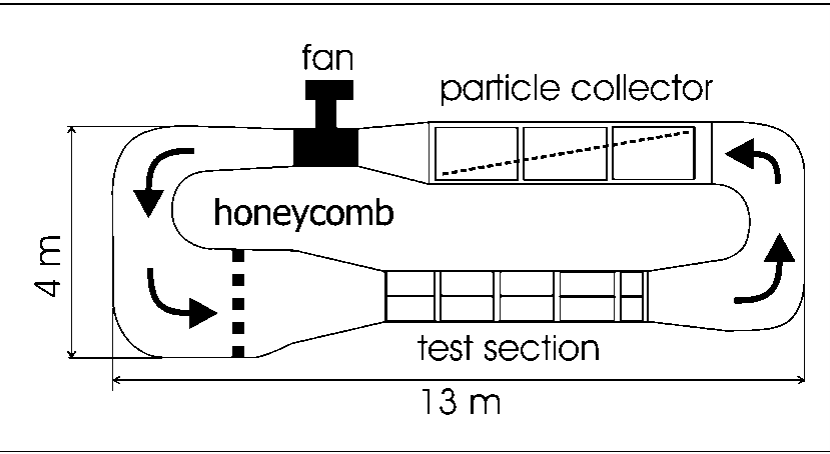

Fig. 2. The wind tunnel at Cemagref, Grenoble, France. The test area is $1.0 \mathrm{~m}$ wide, $0.5 \mathrm{~m}$ high and $4.5 \mathrm{~m}$ long. The wind speed is regulated with the fan, and particles are collected in the upper part of the wind tunnel.

dimensionless volumes obtained at equilibrium for different configurations of dams and mounds. From an engineering point of view, it is necessary to study the most unfavourable situation (e.g. a long snowstorm with low wind speed). Higher wind speeds cause smaller snowdrifts. Therefore a friction velocity of $0.31 \mathrm{~cm} \mathrm{~s}^{-1}$ was chosen, leading to a wind ratio of 1.1. Moreover, this allows a short saltation length to be obtained.

Since the dams and mounds are large, the saturated equilibrium is unlikely to be obtained often. Therefore a different approach to compare the different configurations has to be found.

During initial accumulation (Fig. 1, part A) the dimensionless volume increases nearly linearly with time (solid line). In fact, observed values of dimensionless volume (dotted line) increase very rapidly at first and much more slowly as equilibrium is reached (Iversen, 1980).

Considering a situation where deposition is governed by a topographic feature of height $H$ and lateral width $L$, the deposed material is proportional to the total mass flow rate $Q$, the lateral width $L$ and the experiment's duration $t$.

$$
V_{0} \propto \frac{Q L t}{\sigma} \Rightarrow \frac{V_{0}}{L H^{2}}=A \frac{Q t}{\sigma H^{2}}
$$

$A$ corresponds roughly to $\eta$, the object's collection coefficient of particles proposed by Anno (1984), and to the function $f$ proposed by Iversen $(1980,1984)$.

Iversen proposed the following formulation for the function $f$, which must be determined for each type of configuration.

$$
f\left(\frac{u(H) L}{v}, \frac{h}{H}, \frac{l}{L}, \frac{z_{0}}{H}, \frac{z_{0}^{\prime}}{H}, \frac{\rho}{\sigma}, \frac{U_{\mathrm{F}}}{u_{* \mathrm{th}}}, \frac{u_{*}^{2}}{g H}\right)
$$

Comparing different topographic features governed by the same height and the same lateral width $L$ and for the same experimental conditions (same particle, same speed and same fetch leading to the same mass flow rate), we can consider that the slope of the curve drawn in part A of Figure 1 is representative of the effectiveness of the obstacles, which allows a comparison between the configurations.

\section{MATERIALS AND METHODS}

\subsection{Wind tunnel}

The general design of the wind tunnel is shown in Figure 2. The tunnel is equipped with particle filters to prevent parti-
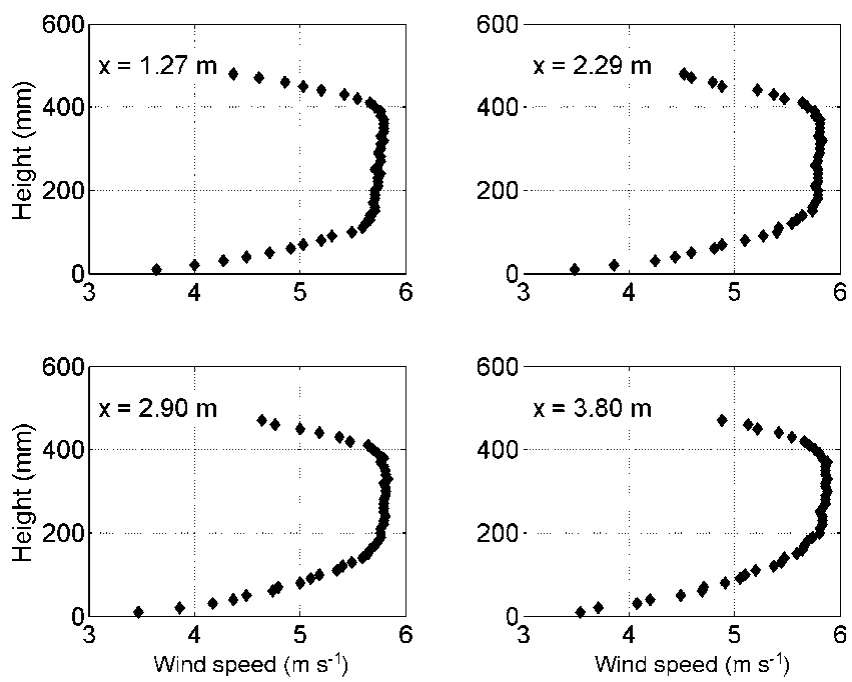

Fig. 3. Development of boundary layer along the wind tunnel ( $x=0$ at the start of the experimental section).

cles from re-entering the test area. The test area is $1.0 \mathrm{~m}$ wide, $0.5 \mathrm{~m}$ high and $4.5 \mathrm{~m}$ long and can be accessed from the side. For the present experiments, the wind tunnel is prepared with triangular turbulence generators at the start of the experimental section to increase the boundary layer depth, yielding a boundary layer depth of $0.2 \mathrm{~m}$ (Fig. 3). The floor of the wind tunnel is covered with sandpaper to increase the surface roughness. The mean wind profile of the boundary layer, measured $3.8 \mathrm{~m}$ downstream of the turbulence generators, shows logarithmic behaviour according to the theory (Fig. 4). Wind and turbulence profiles of flow speed were measured with a constant-temperature hot-wire system. Particles are placed on the floor in the first $2 \mathrm{~m}$ of the test section. On the lateral boundaries of the wind tunnel the edge effect influences the flow (Fig. 5). Therefore, the small-scale model never exceeds $70 \mathrm{~cm}$ in width, and only a central zone $40 \mathrm{~cm}$ wide is surveyed. An area of $10 \mathrm{~cm}$ on the side-walls is kept free of particles. The models are located at the end of the experimental section using the maximum fetch available. Above the models, the roof of the wind tunnel can be removed to allow laser measurements of the depositions. The laser is moved mechanically along a two-

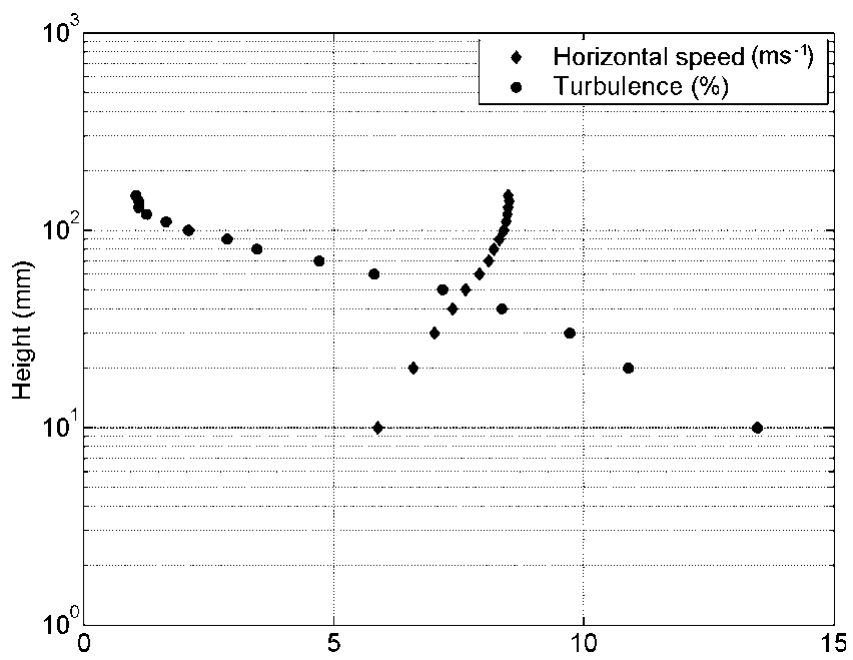

Fig. 4. Example of vertical profiles of velocity and turbulence at $x=3.8 \mathrm{~m}$ (end of the experimental section). 
Table 1. Characteristics of the applied particles.

\begin{tabular}{ccccccccc}
\hline Particles & Particle density $\sigma$ & Bulk density $\gamma$ & $\begin{array}{c}\text { Mean particle } \\
\text { diameter } D_{\mathrm{p}}\end{array}$ & $\begin{array}{c}\text { Measured threshold } \\
\text { friction velocity } \\
u_{* \mathrm{th}} \\
\mathrm{m} \mathrm{s}^{-1}\end{array}$ & $\begin{array}{c}\text { Velocity ratio } \\
u_{*} / u_{* \mathrm{~h}}\end{array}$ & $\begin{array}{c}\text { Calc. fall velocity } \\
U_{\mathrm{F}} \text { for } D_{\mathrm{p}}\end{array}$ & $\begin{array}{c}\text { Fall velocity ratio } \\
U_{\mathrm{p}} / u_{*}\end{array}$ & $\begin{array}{c}\text { Calc. length of } \\
\text { saltation }\end{array}$ \\
\hline Sand & 2650 & 1200 & 115 & 0.28 & 1.1 & 0.72 & 2.3 & $\mathrm{~m} \mathrm{~s}^{-1}$ \\
\hline
\end{tabular}

dimensional grid and is triggered automatically every $0.005 \mathrm{~m}$.

As drift media, washed sand in the range $50<S<250 \mu \mathrm{m}$ is used. The characteristics of the sand are listed in Table 1 . The wind speed is adjusted to be close to the threshold wind speed. This keeps the particle trajectories as short as possible. Depending on the relative humidity of the air, the wind speed in the tunnel varies from $4.5<U_{\mathrm{m}}<5 \mathrm{~m} \mathrm{~s}^{-1}$.

\subsection{The models}

The idealized models of breaking mounds and dams used in this study have the same dimensions as in Hákonardóttir and others (2001). The models are made of polystyrene and are fixed on a ground plate to resist the wind. Table 2 gives an overview of the size and design of the different experiments. Each design is tested for the three wind directions, $0^{\circ}, 45^{\circ}$ and $90^{\circ}$. Accumulation around the models was measured after 1, 2 and 3 hours of drift. The resulting depositions were scanned with the laser at a grid size of $0.005 \mathrm{~m}$. The accumulated volume is calculated for a $0.4 \mathrm{~m}$ wide, $0.8 \mathrm{~m}$ long area covering the centre of the models to avoid unwanted side effects of the wind-tunnel boundaries.

\section{RESULTS}

Two examples are given to illustrate the three-dimensional pattern of the deposition around the mounds. The deposition around experiment $\mathrm{F}$ in Figure 6 shows the up- and downwind drifts after 3 hours. The side drifts of each mound merge into a large drift behind the mounds, while the

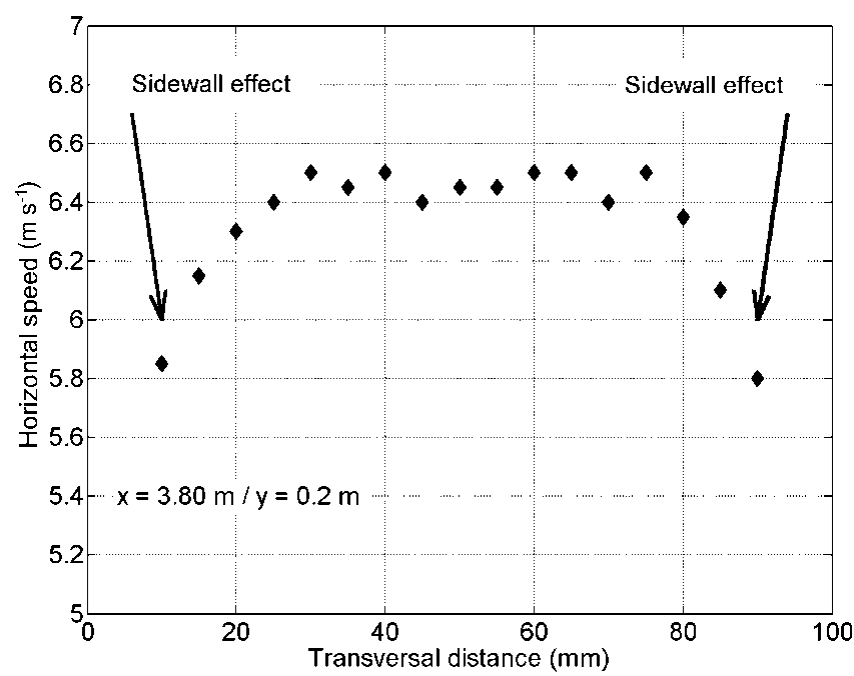

Fig. 5. Example of transversal profile of velocity. intersections between them are kept free by the increased wind speed due to the neighbouring mound. The upwind drifts collect a significant amount of particles close to the mounds, causing a possible problem for their avalanche-retarding effect. The results of a laser scan around low mounds (experiment E) after 2 hours (Fig. 7) demonstrate the symmetry of the depositions in the wind tunnel. The upwind drifts are much smaller than in Figure 6, and the downwind drifts are still separated by the jet streams from the intersections between the mounds.

Results of all experiments are listed in Table 3 and are presented graphically in Figure 8. The dimensionless volumes allow a comparison of the effectiveness of defence structures (see section 2.4). Generally, maximum accumulation takes place with the wind direction at $90^{\circ}$ in the models. On average, 55-65\% fewer particles are deposited at $45^{\circ}$, while the accumulation at $0^{\circ}$ is negligible. The narrow mounds (experiment D) with a limited distance of $3.0 \mathrm{~cm}$ between the mounds are the most effective model to accumulate sand in the experiment at both $90^{\circ}$ and $45^{\circ}$. Less than half the volume is deposited around the $5.0 \mathrm{~cm}$ high dam (experiment G) and two parallel rows at $90^{\circ}$ (experiment $\mathrm{H})$. Smallest accumulations occur around mounds with a smaller relative area at $90^{\circ}$ (experiment $\mathrm{G}$ ) and the two-parallel-rows set-up at $45^{\circ}$ (experiment $\mathrm{H}$ ). It should be noted that, unlike the mounds, dams accumulated most of the deposition on the windward side. More illustrations of the results are given in the final CADZIE (Catastrophic Avalanches: Defence Structures and Zoning in Europe) report (Naaim-Bouvet and others, 2003).

Table 2. Overview of all applied models. $H$ is the height, $B$ the width and $\Delta$ the distance between the mounds. A is the proportion of the cross-sectional area which is blocked by the mounds. All mounds are $4 \mathrm{~cm}$ thick. (Modified from Hákonardóttir and others, 2001)

\begin{tabular}{lrrrrr}
\hline Experiment & $H$ & $B$ & $\Delta$ & $A$ & $H / B$ \\
& cm & cm & cm & & \\
& & & & & \\
\hline A. Low dam & 2.5 & 80.0 & - & 1.0 & - \\
B. Low dam & 3.0 & 80.0 & - & 1.0 & - \\
C. Dam & 5.0 & 80.0 & - & 1.0 & - \\
$\quad$ High dam & 10.0 & 80.0 & - & 1.0 & - \\
D. Narrow mounds & 5.0 & 5.0 & 3.0 & 0.6 & 1.0 \\
E. Low mounds & 2.5 & 5.0 & 3.0 & 0.6 & 0.5 \\
F. High, wide mounds & 5.0 & 15.0 & 10.0 & 0.6 & 0.67 \\
G. Smaller relative area & 5.0 & 10.0 & 15.0 & 0.4 & 0.5 \\
H. Two rows parallel (dist. $30 \mathrm{~cm})$ & 5.0 & 10.0 & 6.0 & 0.6 & 0.5 \\
I. Two rows staggered $($ dist. $30 \mathrm{~cm})$ & 5.0 & 10.0 & 6.0 & 0.6 & 0.5 \\
J. Conical mounds & 5.0 & 10.0 & 0.0 & 0.5 & 0.5 \\
K. Semi-rounded dam & 3.0 & 44.0 & - & - & - \\
& & & & & \\
\hline
\end{tabular}




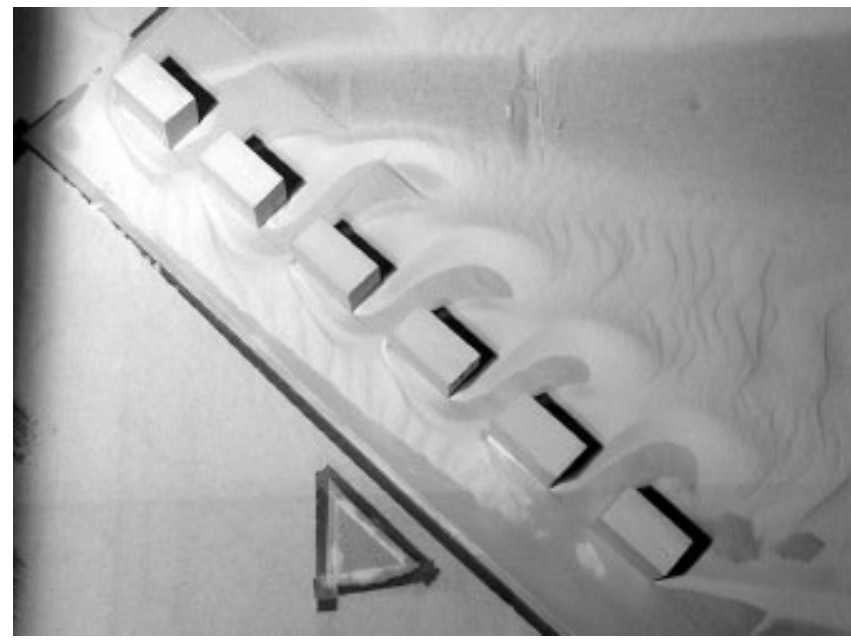

Fig. 6. Picture of the deposition after 3 hours around the high wide mounds (experiment $F$ ) at $45^{\circ}$ wind direction (wind blowing from the left).

\section{DISGUSSION}

The results demonstrate the possibilities of wind-tunnel modelling. The observed depositions depend on the wind direction and the design of the mounds. The wind direction influences all models in the same manner, while the design causes significant differences within the same wind direction. The ratio of the height to the width of the mounds, as well as the size of the gap between the mounds, mainly influences the pattern of the accumulating particles. At $90^{\circ}$ the mounds with the largest retarding effect on avalanches (Hákonardóttir and others, 2001) are also those that collect

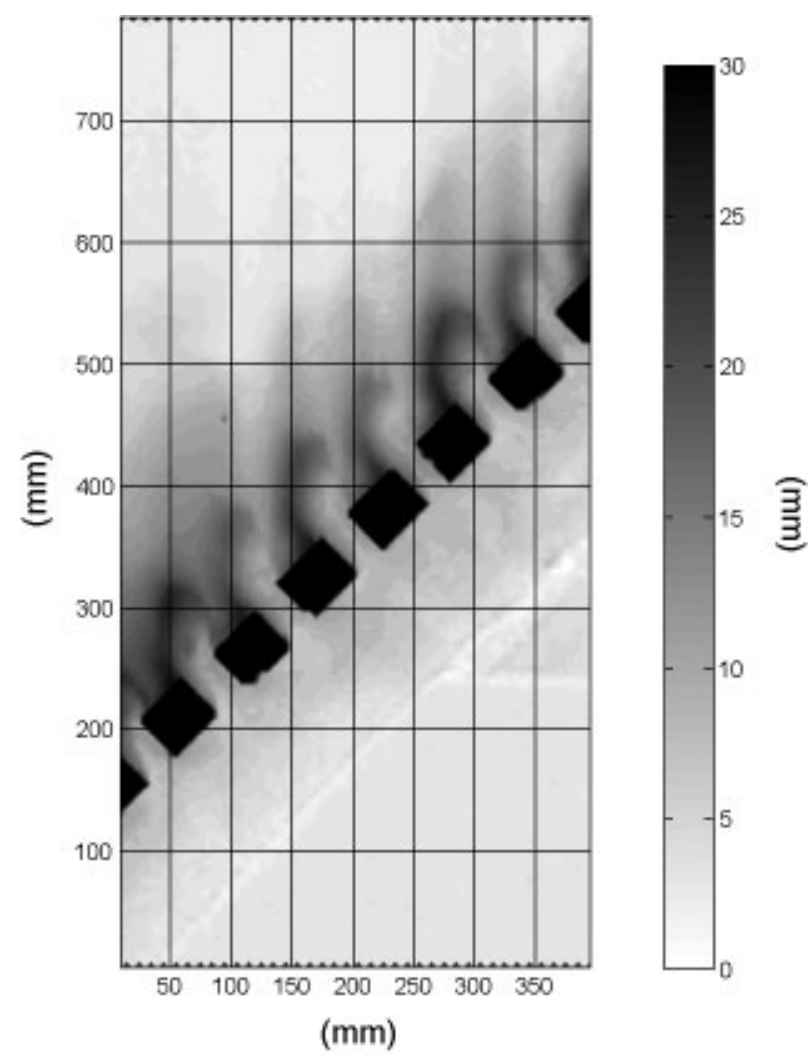

Fig. 7. Plot of the results from a laser scan of the depositions after 2 hours around low mounds (experiment E) at $45^{\circ}$ wind direction.
Table 3. Results from the wind-tunnel experiments after 1, 2 and 3 hours for the tested wind directions $90^{\circ}$ and $45^{\circ}$

\begin{tabular}{|c|c|c|c|c|c|c|}
\hline \multirow[t]{2}{*}{ Experiment } & \multicolumn{3}{|c|}{$90^{\circ}$} & \multicolumn{3}{|c|}{$45^{\circ}$} \\
\hline & 1hour & 2 hours & 3 hours & 1hour & 2 hours & 3 hours \\
\hline A. Dam $2.5 \mathrm{~cm}$ & 2.1 & 1.3 & 1.7 & 2.4 & 2.0 & 1.8 \\
\hline B. Dam $3.0 \mathrm{~cm}$ & 1.6 & 2.0 & 2.5 & 1.8 & 1.7 & 1.8 \\
\hline C. Dam $5.0 \mathrm{~cm}$ & 1.2 & 1.6 & 1.6 & 0.3 & 0.4 & 0.6 \\
\hline Dam $10.0 \mathrm{~cm}$ & too high fo & $r$ the bo & undary & ayer in & the wind & tunnel \\
\hline D. Narrow mounds & 1.4 & 2.8 & 4.1 & 0.6 & 1.2 & 1.5 \\
\hline E. Low mounds & 0.7 & 1.5 & 3.0 & 0.7 & 1.1 & 1.3 \\
\hline $\begin{array}{l}\text { F. High, wide } \\
(\text { limited to } 5 \mathrm{~cm} \text { ) }\end{array}$ & 0.0 & 0.1 & 0.4 & 0.2 & 0.3 & 1.0 \\
\hline G. Smaller rel. area & 0.0 & 0.1 & 0.2 & 0.2 & 0.2 & 0.4 \\
\hline $\begin{array}{l}\text { H. Two rows parallel } \\
\text { dist. } 30 \mathrm{~cm}\end{array}$ & 0.4 & 0.7 & 0.9 & 0.2 & 0.2 & 0.2 \\
\hline $\begin{array}{l}\text { I. Two rows staggered } \\
\text { dist. } 30 \mathrm{~cm}\end{array}$ & 0.1 & 0.4 & 0.6 & 0.2 & No data & 0.3 \\
\hline J. Conical mounds & 0.2 & 0.3 & 0.3 & 0.0 & 0.0 & 0.0 \\
\hline K. Semi-rounded dam & 0.7 & 0.8 & 0.8 & 0.4 & 0.5 & 0.5 \\
\hline
\end{tabular}

Notes: $0^{\circ}$ is not listed because of the very small accumulation. The characteristic size of the dams and mounds is given in Table 2. All volumes are dimensionless $\left(V_{0} / L H^{2}\right)$.
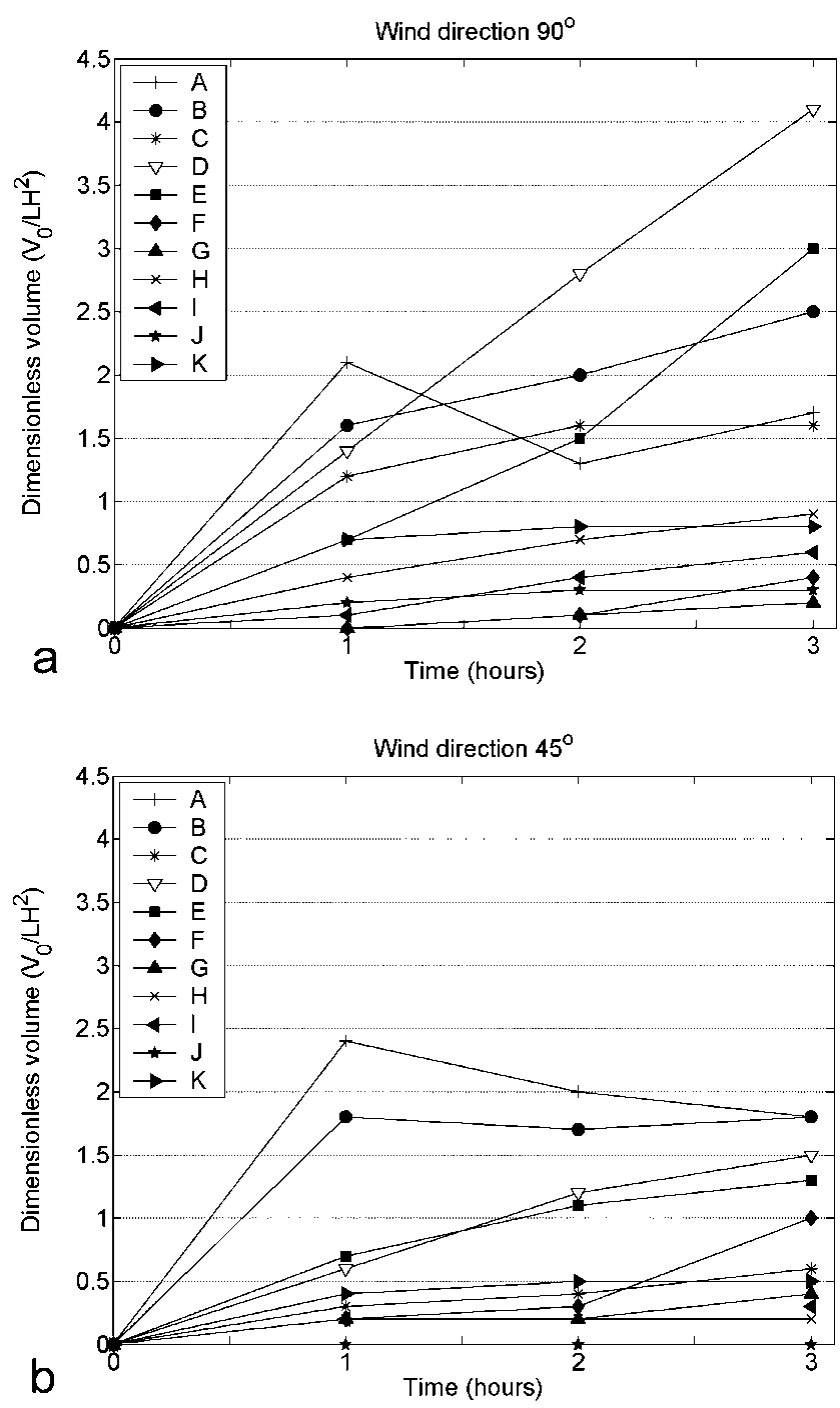

Fig. 8. Overview of the results from all idealized dams as shown in Table 3. All volumes are dimensionless $\left(V_{0} / L H^{2}\right)$, allowing comparison of the effectiveness of defence structures. The wind directions are $90^{\circ}(a)$ and $45^{\circ}(b) .0^{\circ}$ is not depicted because of the very small accumulation. The geometry of the dams is described in Table 2. 
the most particles by drift. The same is true of the continuous dams. Conversely, less retarding effect on the avalanches causes less accumulation due to drifting snow. This shows that similar processes of fluid mechanics are involved in both the avalanche flow and drifting snow around the mounds and dams. But it also illustrates a conflict of interests when an optimal solution for the combination of effective avalanche retarding and little drift accumulation is required.

The deposition pattern in the central part of the idealized models shows that the airflow in the wind tunnel is symmetric and uniform. Side effects towards the lateral wind-tunnel walls were excluded from the results by using only the central $40 \mathrm{~cm}$ for accumulation calculations. Wind speed and the erosion bed geometry were controlled frequently and adjusted if necessary.

A significant source of error may be introduced by variations in relative humidity. This influences the cohesion between the sand grains and the threshold friction velocity, leading to a different velocity ratio for different weather types. The vertical resolution of the applied laser for the scanning of the depositions is $\pm 0.5 \mathrm{~mm}$. This error is amplified by the mechanical and laser triggering system used to measure along a regular grid. A vertical and horizontal error of $\pm 2.0 \mathrm{~mm}$ has to be considered in the results, which is high compared to the measured accumulation in some of the experiments.

The method applied allows the results of different mounds and dams to be compared with each other, giving relative results of the different designs. A transfer to real scale was not intended by this study and is difficult due to unsatisfied similarity criteria.

\section{CONGLUSION}

Snow accumulation around avalanche defence structures can decrease the effective height and retarding effect of the structure. Wind-tunnel tests of different avalanche defence structures, dams as well as mounds, were used to study the amount of accumulation around the structures. Accumulation occurs on both the windward and the lee zone of the structures, decreasing their retarding effect. All structures accumulate the most particles at wind from $90^{\circ}$ on the structure compared to other wind directions. Narrow mounds with short spacing lead to significantly more particle deposition than structures with a limited effective area. From a snowdrift point of view, the best choice is mounds with a limited area covering the avalanche path. At a wind direction of $0^{\circ}$ on the structure, accumulation is minimal and insignificant for the retarding effect of the structure. The set-up applied allows comparison of accumulation between models, but transfer of the results to full scale is difficult because of similarity criteria that cannot be met.
To increase the significance of wind-tunnel studies, standard test cases (for scales between 1/250 and 1/500) must be run on a real-world scale such that individual wind-tunnel set-ups can be tested as was previously done for snow fences (for scales between 1/50 and 1/100) (Iversen, 1981; NaaimBouvet, 1994). Documentation of three-dimensional drift patterns by laser is a suitable method that can be improved by more accurate laser systems.

\section{ACKNOWLEDGEMENTS}

Thanks to H. Bellot for his tireless assistance in the wind tunnel, and S. Frauciel for language advice. This programme was founded by European Union (CADZIEEVG1-1999-00009) during the fifth framework programme. Additional funding was provided by Cemagref and the Norwegian Geotechnical Institute.

\section{REFERENGES}

Anno, Y. 1984. Requirements for modeling a snowdrift. Cold Reg. Sci. Technol., 8(3), 241-252.

Bagnold, R. A. 1941. The physics of blown sand and desert dunes. London, Methuen and Co.

Finney, E. A. 1939. Snow drift control by highway design. East Lansing, MI, Michigan State College Engineering Experiment Station. (Bulletin 86.)

Hákonardóttir, K. M., T. Jóhannesson, F. Tiefenbacher and M. Kern. 2001. A laboratory study of the retarding effect of breaking mounds in 3, 6 and $9 \mathrm{~m}$ long chutes. Reykjavík, Veðurstofa Íslands. (Technical report VI-G01007ÚR02.)

Iversen, J. D. 1980. Drifting-snow similitude-transport-rate and roughness modeling. F. Glaciol., 26(94), 393-403.

Iversen, J. D. 1981. Comparison of wind-tunnel model and full-scale snow fence drifts. F. Wind Eng. Ind. Aerodyn., 8, 231-249.

Iversen, J. D. 1984. Comparison of snowdrift modeling criteria: commentary on "application of Anno's modeling conditions to outdoor modeling of snowdrifts". Cold Reg. Sci. Technol., 9(3), 259-265.

Kind, R. J. 1986. Snowdrifting: a review of modelling methods. Cold Reg. Sci. Technol., 12(3), 217-228.

Mellor, M. 1965. Blowing snow. CRREL Monogr., III-A3c.

Michaux, J.-L., F. Naaim-Bouvet, K. Kosugi, A. Sato and T. Sato. 2002. Étude en soufflerie climatique (Cryospheric Environment Simulator) de l'influence du type de grain de neige et du régime d'écoulement sur la formation d'une congère. La Houille Blanche, 2002 (6-7), 79-83.

Naaim-Bouvet, F. 1995. Comparison of requirements for modeling snowdrift in the case of outdoor and wind-tunnel experiments. Surv. Geophys., 16(5-6), 711-727.

Naaim-Bouvet, F. 1997. Contribution à la modélisation physique et numérique du transport de neige par le vent. (Thèse de doctorat, Université Joseph Fourier, Grenoble.)

Naaim-Bouvet, F. and M. Naaim. 1998. Snowdrift modeling in a wind-tunnel: vertical and horizontal variation of the snow flux. Ann. Glaciol. 26, 212-216.

Naaim-Bouvet, F. and 6 others. 2003. WP3: interaction of powder avalanches with defence structures. Grenoble, Cemagref. (CADZIE/catastrophic avalanches/defence structures and zoning in Europe. Final report EVG1199-00009.)

Tabler, R. D. 1980. Self-similarity of wind profiles in blowing snow allows outdoor modeling. f. Glaciol., $26(94), 421-432$. 